\title{
The Effects of Mobile-Assisted Language Learning (MALL) on Korean College Students' English-Listening Performance and English-Listening Anxiety
}

\author{
Yoon Jung Kim \\ Pusan National University, South Korea
}

\begin{abstract}
Despite the increasing significance of mobile technology in EFL (English as a Foreign Language) learning, most empirical studies to date have been restricted to vocabulary acquisition, grammar learning, and speaking/writing development. However, the present study focuses its attention on changes in Korean college students' listening performance by making use of diverse mobile applications. In addition, this paper distinctively examines how these students' anxiety levels in English listening may differ after implementing mobile-assisted language learning (MALL). Ten Korean college students preparing for the TOEFL (Test of English as a Foreign Language) participated in this mixed-method study. A background questionnaire, a sample TOEFL listening test, and an anxiety-level questionnaire were distributed to them as a starting point. During a 6-week treatment period, the control group continued using traditional learning materials (i.e., textbooks and MP3 files), whereas the experimental group adopted MALL. Then, once again each student took the TOEFL listening test and filled out the anxiety-level questionnaire-both were similar to the pretests. As a last step, the researcher interviewed the participants individually. The research findings show that the experimental group somewhat enhanced TOEFL listening comprehension, while the control group remained almost the same. The influence of MALL stands out with respect to the participants' English-listening anxiety: only the score of the experimental group was lowered. The last significant conclusion was that, regardless of the group, students' English-listening performance was negatively correlated with their English-listening anxiety both in pretest and in posttest. The results from this study could offer a venue for instructors who teach English listening within EFL contexts.
\end{abstract}

Keywords: MALL, applications, listening, TOEFL, performance, anxiety, Korean college students

\section{Introduction}

With the advent of highly developed technology, Internet tools have been incorporated into educational settings. In an attempt to conform to this rapid development and to supplement traditional language classrooms, educators and researchers have begun to utilize these digital sources. Computer-assisted language learning (CALL) has had a great impact on language classrooms, as Internet resources allow teachers to retrieve the most recent and pertinent information (Moore et al., 1998). Moreover, teachers, as well as students, can search and access a wide variety of authentic materials through the Internet, and students can study individually and progress at their own speeds. CALL also stands out in terms of providing immediate and precise feedback.

In spite of CALL's advantages, a new concept-mobile-assisted language learning (MALL) — has been increasingly capturing attention, as a mobile phone is a portable device that encompasses all of the advantages discussed above. Some studies have even concluded that learners prefer short lessons on mobile phones over those on computers (e.g., Thornton \& Houser, 2005). Relatively few studies, however, have delved into the pedagogical use of MALL with respect to listening comprehension (Sze, 2006). This is partly because listening comprehension has been considered a rather passive activity. However, following Vandergrift's (1999) point of view, the present study viewed it as an active and complex process in which the listener must be well aware of phonological features (Henrichsen, 1984) and understand vocabulary and grammatical structures. Additionally, 
cognitive factors can make such a situation more complex. That is, it can be challenging to remember items in the target language (Richards, 1983).

Although previous MALL studies have discussed the positive influence of MALL on foreign-language (FL) performance, none thus far have investigated the relationship between MALL and FL anxiety. Since anxiety has long been considered one of the affective factors (i.e., aptitude, motivation, emotion, and anxiety) strongly influencing FL learning (Gregersen, 2005; MacIntyre, 1995a), it needs further consideration in the field of MALL as well. The current study focused on examining FL anxiety (i.e., English anxiety in this case) specifically in the area of listening rather than viewing, in general, since both language performance and language anxiety might differ between one specific language skill and overall language skills (Saito et al., 1999).

In this sense, the present study aimed to investigate how MALL influenced students' FL-learning performance as well as FL anxiety using the following research questions:

- Research question 1: Did mobile-assisted language learning (MALL) affect Korean college students' Test of English as a Foreign Language (TOEFL) listening outcomes?

- Research question 2: Did mobile-assisted language learning (MALL) affect Korean college students' levels of English listening anxiety?

- Research question 3: Was there any relationship between Korean college students' English-listening performance and their English-listening anxiety?

\section{Literature Review}

\subsection{Mobile-Assisted Language Learning (MALL)}

Since Chinnery (2006) coined the term mobile-assisted language learning (MALL), the interest in and the ongoing discussion of this issue have been growing. Although a disagreement still exists about whether MALL should be considered a part of CALL or viewed distinctively, MALL is valuable "in its use of personal, portable devices that enable new ways of learning, emphasizing continuity or spontaneity of access and interaction across different contexts of use" (Kukulska-Hulme \& Shield, 2008, p. 273). While MALL was originally viewed very restrictively and concentrated on the mobility of the device, the focus has moved to the user (Laouris \& Eteokleous, 2005, as cited in Jang \& Kim, 2015). That is, the mobility of the learners and the mobility of learning are now involved as well (El-Hussein \& Cronje, 2010).

In recent years, a wide variety of studies have examined the potential of mobile devices to facilitate FL learning (Golonka et al., 2012). Short message service (SMS) was the method most frequently used to implement MALL. In terms of language skill, vocabulary acquisition has been a major topic in MALL-research. Accordingly, many studies have found that SMS has a positive influence on vocabulary instruction (e.g., Levy \& Kennedy, 2005; Thornton \& Houser. 2005). For instance, participants from Levy and Kennedy (2005) not only experienced enhanced Italian vocabulary abilities but also held positive perceptions toward MALL.

Of the few studies examining the effects of MALL on listening comprehension, many have focused on the podcast, which is defined as "a multimedia digital file made available on the Internet for downloading to a portable media player, computer, etc." (New Oxford American Dictionary, 2005; e.g., Lu, 2007; Qasim \& Fadda, 2013). The podcast is beneficial because it is automatically downloadable once a person subscribes. Qasim and Fadda (2013) have claimed that the podcast is a great source that may provide abundant listening materials both inside and outside the classroom. In addition, some empirical studies have demonstrated the positive effects of podcasts in increasing students' intrinsic and extrinsic motivation (e.g., Hegelheimer \& O-Bryan, 2007). Still, the scope of studies is quite limited. Further research adopting diverse mobile applications is needed.

\subsection{Foreign-Language (FL) Anxiety}

Anxiety is defined as a "subjective feeling of tension, apprehension, nervousness, and worry associated with an arousal of the autonomic nervous system" (Horwitz et al., 1986, p. 125). A number of researchers have found that students commonly experience anxiety to a certain extent (Saito \& Samimy, 1996); therefore, it becomes a 
primary factor deciding students' academic performance. Several symptoms indicate anxiety, including perspiration, stomach ache, rapid heartbeat, and elevated pulse rate (Steinberg \& Horwitz, 1986). In addition, actions such as freezing up when asked to perform, forgetting what was learned in class, or refusing to speak can be caused by anxiety as well (Young, 1990). In terms of behaviour factors, anxious learners often show avoidance, such as by missing class, delaying homework, coming to class unprepared, or objecting to FL requirements (Horwitz et al., 1986).

Anxiety is one of the strongest predictors of FL success (Oxford, 1999). A number of studies (e.g., Horwitz et al., 1986) have been conducted to discover the relationship between FL anxiety and learners' FL achievement, and a majority have found the two to be negatively correlated. These studies often used the original or adapted version of Horwitz et al.'s (1986) Foreign Language Classroom Anxiety Scale (FLCAS). The FLCAS is comprised of items regarding communication apprehension, test anxiety, and the fear of negative evaluation. However, strictly speaking, no consensus has been reached on whether FL anxiety results in low FL performance (Horwitz, 2000; MacIntyre, 1995b) or whether low FL performance merely leads to FL anxiety (Sparks \& Ganschow, 1991).

Among the four types of English-language skills, speaking has been the area in which EFL students demonstrate the highest level of FL anxiety (Horwitz, 2001). Thus, many anxiety studies have tended to concentrate on this aspect (Woodrow, 2006). Compared to speaking anxiety, listening anxiety in FL learning has yet to be thoroughly studied (Elkhafaifi, 2005) because teachers often do not focus on listening in their FL classes. Because they may regard listening comprehension as a passive skill, they do not expect their students to suffer from deficits in this area. However, listening anxiety should be actively examined, since listening and speaking occur simultaneously during verbal interactions (Vogely, 1998). Elkhafaifi (2005), for example, conducted research to examine the relationships between specific listening anxiety and general FL anxiety.

\section{Methodology}

\subsection{Participants}

Ten Korean undergraduate students voluntarily chose to participate in the present study. None of the participants were English-related majors. They had studied English for at least 10 years, and three had also experienced living in an English-speaking country. All participants had prepared for the TOEFL test for less than 2 months, mostly to apply to an exchange student program. Before embarking on the current study, only two participants out of the ten reported experience with using a smartphone or a tablet PC for academic purposes. In addition, during the study all members from the experimental group only used smartphones for MALL.

The participants were divided into two groups of five students each. The first participant group, the so-called control group, received no special treatment and continued their self-study only using typical textbooks and MP3 files. The experimental group was exposed to MALL in order to regularly listen to authentic texts via diverse smartphone applications. All experimental group members reported that they quite regularly used MALL on the move. The topics of their MALL using were not restricted.

\subsection{Instrument}

First, an actual sample of a TOEFL listening test was given during both the pretest and the posttest. Following directions for each part (i.e., part 1 and part 2), each student was required to answer 34 questions. Each part consisted of three separate lectures, and diverse questions were included, such as main topic/purpose, details, match/ordering, and inference. Since the TOEFL is a standardized English test that individuals are required to take in order to enter higher education in the United States, it can be assumed to be a valid and reliable measure for indicating learners' English proficiencies.

Second, in terms of the background questionnaire, several variables (e.g., major, living experience in an English-speaking country, experience of taking the TOEIC/TOEFL, English-listening strategy, MALL exposure) were asked about for later data analysis. 
Third, a 5-point Likert-type anxiety level test, ranging from 1 (strongly disagree) to 5 (strongly agree), was adapted from the original anxiety scale. The test was comprised of 42 items, including a few reversed items, inquiring about Korean college students' English listening anxiety. For participants' better understanding, the researcher translated all items into the Korean language.

The final instrument was the interview protocol. Although detailed follow-up and further questions varied from one participant to another, preliminary questions were devised in advance.

\subsection{Data Collection and Analysis Procedures}

A researcher posted a flyer at one Korean university community website and recruited target participants who were currently preparing to take the TOEFL. The current research employed a mixed-method approach. Stage 1 began with signing an informed consent form. Then, students were required to take one set of TOEFL listening tests, which were similar to the actual TOEFL listening comprehension test. They were then given a survey with two sections - a background questionnaire and an anxiety level questionnaire. This entire pretest procedure took 60 to 70 minutes.

No other restriction was imposed upon the control group. They were only required to continue their TOEFL self-study. However, the researcher recommended a number of mobile applications (e.g., TED, TuneIn Radio, Overcast, Listening Drill), available at both the Apple App Store and Android Google Play for free, to the experimental group. They were urged to use these applications at least 10 minutes per day during the 6-week treatment period to regularly expose themselves to authentic or academic English-listening texts. However, there was no intervention regarding participants' app choices or their patterns of usage.

After the treatment period, all participants took a similar type of TOEFL listening test and anxiety level test. For the last step, the researcher conducted a semistructured interview with all participants. All interviews were audiorecorded with the participants' permission. The posttest procedure, including the postinterview, lasted no more than 1 hour and 30 minutes. The incentives were differentially provided, since the experimental group participants were required to devote extra time and effort.

Data analysis was conducted in two stages, and the quantitative data were statistically analysed. For qualitative data analysis, the researcher adopted grounded theory (Strauss \& Corbin, 1998) and identified emerging themes.

\section{Results and Discussions}

\subsection{Influence of MALL on English-Listening Outcomes}

Table 1 indicates that while the mean score of control group's posttest was almost similar to that of the pretest, the experimental group's TOEFL listening score was somewhat increased.

TABLE I: Descriptive Statistics of Two Groups' TOEFL Listening Test

\begin{tabular}{lllll}
\hline \hline \multirow{2}{*}{ Test } & \multicolumn{2}{l}{ Experimental group $(\mathrm{N}=5)$} & & \multicolumn{2}{c}{ Control group $(\mathrm{N}=5)$} \\
\cline { 2 - 5 } & $\mathrm{M}$ & $\mathrm{SD}$ & $\mathrm{M}$ & $\mathrm{SD}$ \\
\hline Pretest & 10.80 & 4.87 & 18.40 & 6.07 \\
Posttest & 12.60 & 5.55 & 18.60 & 1.52 \\
\hline \hline
\end{tabular}

The qualitative data from the interview revealed almost similar results, although students' self-perceived performance and their actual ability often mismatched in a number of studies. For the control group members, even though their listening scores were much higher than those of the experimental group members in both pretest and posttest, they still seemed to lack the confidence in their English-listening comprehension. Even one participant (C4) who had improved most (from score 8 to 17), still reported she had very low English-listening ability. This result may be partly due the fact that Korean students usually tend to say humbly compared to the students from Western culture. In a similar vein, the experimental group members' comments were noticeable as they seemed to feel the opposite. Despite the fact that four out of five of them had no previous MALL experience, they perceived MALL as an effective instructional tool to improve their TOEFL listening scores 
after the treatment period. For example, E4 stated, "I switched on TED and other listening applications while I was in my lab...constantly listening to English was very helpful." Another participant (C1) also made a contrast with her experience learning French via MALL.

\subsection{Influence of MALL on English-listening Anxiety}

Table 2 shows an interesting result. Not only did the level of anxiety decrease for the experimental group, but interestingly the control group was increased.

TABLE II: Descriptive Statistics of Two Groups' Listening Anxiety

\begin{tabular}{lllll}
\hline \multirow{2}{*}{ Test } & \multicolumn{2}{l}{ Experimental group $(\mathrm{N}=5)$} & & \multicolumn{2}{c}{ Control group $(\mathrm{N}=5)$} \\
\cline { 2 - 5 } & $\mathrm{M}$ & $\mathrm{SD}$ & $\mathrm{M}$ & $\mathrm{SD}$ \\
\hline Pretest & 3.45 & .60 & 2.54 & .64 \\
Posttest & 2.93 & .74 & 2.80 & .69 \\
\hline \hline
\end{tabular}

[Excerpt 1] E3: ...usually what we hear in English is a short dialogue...but for the TOEFL test, we hear mostly long lectures.

Therefore, I confronted challenges when studying for the TOEFL listening... However, after I regularly listened to various topics through apps, I felt like I was getting accustomed to long conversations...even though it's in English. Certainly I became less anxious about English listening.

[Excerpt 2] C3: After I prepare for the TOEFL, I feel like my listening anxiety is increased. Before that, I wasn't afraid of talking with foreigners in English. But this could be partly because of the nature of the exam. Anyway, I'm more nervous these days. ... And unfortunately studying TOEFL listening with traditional materials bores me.

Given excerpts also support the quantitative finding. As discussed above, the experimental group members' English-listening comprehension abilities were still lower than the control group members in the posttest. In other words, based upon previous research it is normally expected that a learner with low FL proficiency have a high level of FL anxiety. However, the findings from this study were contradictory, and the interview data revealed how much influential MALL was on the Korean college students' level of anxiety in English-listening. In consistent with Jang and Kim (2015)'s study, students found to be sensitive about authentic materials. For instance, E5 said that by using smartphone applications, she could unlimitedly listen to English lectures when commuting to school. In addition, some participants said they used such apps during free time or in bed.

\subsection{A Relationship Between English-Listening Performance and English-Listening Anxiety}

Table 3 below demonstrates one commonality of both groups: English-listening anxiety was one of the strongest predictors inhibiting all participants' English-listening comprehension. The pretest showed a statistical difference at $\alpha=.05$ level ( $\mathrm{p}$ <.05). In contrast, posttest was insignificantly different.

TABLE III: Correlations between English-Listening Performance and English-Listening Anxiety

\begin{tabular}{llc}
\hline \hline & Pretest & Posttest \\
\hline $\begin{array}{l}\text { Pearson correlation } \\
\text { coefficient }\end{array}$ & $-.752 *$ & -.592 \\
Sig. & .012 & .071 \\
$\mathrm{~N}$ & 10 & 10 \\
\hline \hline
\end{tabular}

All interview data conformed to this result, and Korean college students explicitly showed their opinion toward a close relationship between English-listening anxiety and English-listening performance. Moreover, majority of them recognized English proficiency in general also might decrease their English-listening performance.

\section{Conclusion}

In spite of the limitation of small sample size, this research is valuable. First, with respect to the study design, it adopted a mixed-method; therefore, it could examine the participants' opinions thoroughly enough to provide detailed explanation on the quantitative data. Second, it was one of the few studies examining changes of learners' performance and anxiety during the given time period, rather than only focusing on a single moment. 
Third, present study uniquely investigated an influence of MALL on learners' FL anxiety. Previous studies were restricted to viewing simply MALL experiences or relationships between MALL and FL performance. Forth, researchers have not paid much attention to positive influence of MALL on FL listening performance. Last, this study uniquely moved beyond the scope of the podcasts.

The findings from present study may yield implications to both researchers and educators. This study set a foundation for similar research in other EFL contexts. Furthermore, case studies, examining participants during longer period of time (i.e., one semester or one year), will give potential for researchers, since the 6-week treatment period also drew significant findings. In addition, observing how MALL influences on other language skills is also promising. In terms of the pedagogical implications, teachers should find ways to incorporate MALL both inside and outside their FL listening classes. Moreover, in order to maximize effectiveness of MALL, teachers' control may be required at some extent.

\section{References}

[1] M. G. Chinnery, "Going to the MALL: Mobile assisted language learning," Language Learning and Technology, vol. 10, pp. 9-16, January 2006.

[2] M. O. M. El-Hussein, and J. C. Cronje, "Defining mobile learning in the higher education landscape," Educational Technology \& Society, vol. 13, pp. 12-21, October 2010.

[3] H. Elkhafaifi, "Listening comprehension and anxiety in the Arabic language classroom," Modern Language Journal, vol. 89, pp. 206-222, Summer 2005.

https://doi.org/10.1111/j.1540-4781.2005.00275.x

[4] E. M. Golonka, A. R. Bowles, V. M. Frank, D. L. Richardson, and S. Freynik, "Technologies for foreign language learning: A review of technology types and their effectiveness," Computer Assisted Language Learning, vol. 27, pp. 70-105, September 2012.

https://doi.org/10.1080/09588221.2012.700315

[5] T. S. Gregersen, "Nonverbal clues: Clues to the detection of foreign language anxiety," Foreign Language Annals, vol. 38, pp. 388-396, September 2005.

https://doi.org/10.1111/j.1944-9720.2005.tb02225.x

[6] L. E. Henrichsen, "Sandhi-variation: A filter of input for learners of ESL," Language Learning, vol. 34, pp. 103-123, September 1984.

https://doi.org/10.1111/j.1467-1770.1984.tb00343.x

[7] E. K. Horwitz, "It ain't over til it's over: On foreign language anxiety, first language deficits, and the confounding of variables," Modern Language Journal, vol. 84, pp. 256-259, Summer 2000.

https://doi.org/10.1111/0026-7902.00067

[8] E. K. Horwitz, "Language anxiety and achievement," Annual Review of Applied Linguistics, vol. 21, pp. 112-126, March 2001.

https://doi.org/10.1017/S0267190501000071

[9] E. K. Horwitz, M. B. Horwitz, and J. A. Cope, "Foreign language classroom anxiety," Modern Language Journal, vol. 70, pp. 125-132, Summer 1986.

https://doi.org/10.1111/j.1540-4781.1986.tb05256.x

[10] E.-J. Jang, and J.-Y. Kim "Uses of smartphone apps for English listening practice," Studies in English Education, vol. 20, pp. 27-53, March 2015.

[11] A. Kukulska-Hulme, and L. Shield, "An overview of mobile assisted language learning: From content delivery to supported collaboration and interaction," ReCALL, vol. 20, pp. 271-289, September 2008.

https://doi.org/10.1017/S0958344008000335 
[12] M. Levy, and C. Kennedy "Learning Italian via Mobile SMS," in Mobile Learning: A Handbook for Educators and Trainers, A. Kukulska-Hulme, and J. Traxler, Eds. London: Taylor and Francis, 2005, ch. 7, pp. 76-83.

[13] J. Lu. (2007). Podcasting: A fresh solution for old problems. Wireless Ready Symposium E-Proceedings. [Online]. pp. 83-95. Available:

http://opinion.nucba.ac.jp/ thomas/AngLu.pdf

[14] P. D. MacIntyre, "How does anxiety affect second language learning? A reply to Sparks and Ganschow," Modern Language Journal, vol. 79, pp. 90-99, Spring 1995a.

https://doi.org/10.1111/j.1540-4781.1995.tb05418.x

[15] P. D. MacIntyre, "On seeing the forest and the trees: A rejoinder to Sparks and Ganschow," Modern Language Journal, vol. 79, pp. 245-248, Spring 1995b.

https://doi.org/10.1111/j.1540-4781.1995.tb05438.x

[16] Z. Moore, B. Morales, and S. Carel, "Technology and teaching culture: Results of a state survey of foreign language teachers," CALICO Journal, vol. 15, pp. 109-128, 1998.

https://doi.org/10.1558/cj.v15i1-3.109-128

[17] A. O-Bryan, and V. Hegelheimer, "Integrating CALL into the classroom: The role of podcasting in an ESL listening strategies course," ReCALL, vol. 19, pp. 162-180, May 2007.

https://doi.org/10.1017/S0958344007000523

[18] R. L. Oxford, "Anxiety and the Language Learner: New Insights," in Affect in Language Learning, J. Arnold, Ed. Cambridge, U.K.: Cambridge University Press, 1999, pp. 58-67.

[19] N. A. Qasim, and H. A. Fadda, "From Call to Mall: The effectiveness of podcast on EFL higher education students' listening comprehension," English Language Teaching, vol. 6, pp. 30-41, 2013.

[20] J. C. Richards, "Listening comprehension: Approach, design, procedure," TESOL Quarterly, vol. 17, pp. 219-240, 1983.

https://doi.org/10.2307/3586651

[21] Y. Saito, E. K. Horwitz, and T. J. Garza, "Foreign language reading anxiety," Modern Language Journal, vol. 83, pp. 202-218, Summer 1999.

https://doi.org/10.1111/0026-7902.00016

[22] Y. Saito, and K. K. Samimy, "Foreign language anxiety and language performance: A study of learner anxiety in beginning, intermediate, and advanced-level college students of Japanese," Foreign Language Annals, vol. 29, pp. 239-251, Summer 1996.

https://doi.org/10.1111/j.1944-9720.1996.tb02330.x

[23] R. Sparks, and L. Ganschow, "Foreign language learning differences: Affective or native language aptitude differences?," Modern Language Journal, vol. 75, pp. 3-16, Spring 1991. https://doi.org/10.1111/j.1540-4781.1991.tb01076.x

[24] F. S. Steinberg, and E. K. Horwitz, "The effect of induced anxiety on the denotative and interpretive content of second language speech,” TESOL Quarterly, vol. 20, pp. 131-136, March 1986. https://doi.org/10.2307/3586395

[25] P. Sze, "Developing students' listening and speaking skills through EFL podcasts," Educational Journal, vol. 34, pp. 115-134, Winter 2006.

[26] The New Oxford American Dictionary, 2nd ed. New York, NY: Oxford University Press, 2005.

[27] P. Thornton, and C. Houser, "Using mobile phones in English education in Japan," Journal of Computer Assisted Learning, vol. 21, pp. 217-228, 2005. 
https://doi.org/10.1111/j.1365-2729.2005.00129.x

[28] L. Vandergrift, "Facilitating second language listening comprehension: Acquiring successful strategies," ELT Journal, vol. 53, pp. 168-176, July 1999.

https://doi.org/10.1093/elt/53.3.168

[29] A. Vogely, "Listening comprehension anxiety: Students' reported sources and solutions," Foreign Language Annals, vol. 31, pp. 67-80, 1998.

https://doi.org/10.1111/j.1944-9720.1998.tb01333.x

[30] L. Woodrow, “Anxiety and speaking English as a second language," Regional Language Centre Journal, vol. 37, pp. 308-328, December 2006.

https://doi.org/10.1177/0033688206071315

[31] D. J. Young, “An investigation of students' perspectives on anxiety and speaking," Foreign Language Annals, vol. 23, pp. 539-553, December 1990.

https://doi.org/10.1111/j.1944-9720.1990.tb00424.x 